\title{
Evaluation of the Demographic Features of Eye Loss in Turkey
}

\author{
Korhan Fazil
}

Department of Ophthalmic Plastic and Reconstructive Surgery, Beyoglu Eye Training and Research Hospital, Istanbul, Turkey

\begin{abstract}
Objectives: To investigate the causes of eye loss in different age groups and the distribution of age and sex among these patients.

Methods: The medical records of 816 patients (504 men, 312 women) with eye loss due to different etiologies were evaluated retrospectively for this study. Patients were divided into four age groups (preschool, school, adolescence and adulthood) and causes of eye loss were grouped as follows: trauma, postoperative and other causes (infection, tumor, congenital diseases). Pearson's Chi-square test was used to compare the causes of eye loss with age sex and the affected side of the patients.

Results: The mean age was $12.6 \pm 13.6$ (range, 0-76) years. There were 317 patients $(38.8 \%)$ in group 1,214 patients $(26.2 \%)$ in group 2, 107 patients $(13.1 \%)$ in group 3, and 178 patients $(21.8 \%)$ in group 4$)$. The most frequent etiologic factor of eye loss among all the patients and individually in each group was trauma $(p<0.00 \mathrm{I})$. The percentage of trauma tended to increase by age until the age of 20 years. After that, the predominance of other causes of eye loss increased. Fortunately, the overall number of patients with eye loss tended to decrease by age. Traumatic etiologies were more frequently seen in male (68\%) population, whereas other causes (infection, tumor and natal diseases) of eye loss were seen more in the female population $(57.7 \%)(p<0.001)$.

Conclusion: The young adult males are more prone to work-related accidents resulting in eye loss. Thus, the preventive measures are very important to reduce the traumatic eye injuries leading to workforce loss.

Keywords: Congenital, eye loss, infection, postoperative, trauma, tumor.
\end{abstract}

\section{Introduction}

The loss of an eye is a condition that may cause significant physical and emotional stress because of facial disfigurement (I). Therefore, replacing a lost eye with an artificial eye is very important to restore the physical and physiologic health by improving facial esthetics and improving social acceptance (2). Using an ocular prosthesis is important for esthetics and it protects the socket from dust and foreign bodies prevent the accumulation of tear fluid in the socket and preserve facial development (3).

The use of ocular prostheses can be traced back to 2600
B.C. in China and Egypt. In Egypt, different materials, such as precious stones, bronze, copper, gold, and pottery, were used for ocular prostheses (4). In the sixteenth century, a French doctor, Ambroise Paré, designed the first actual ocular prosthesis called "emblepharon." Although his initial prosthesis was made of gold and silver, he improved his design using glass and porcelain, which resulted in a prosthesis shape change from spheres to the shell-type prosthesis (5). By the twentieth century, acrylic prostheses gained popularity over glass because it was easier to construct and had a much longer life $(2,4)$. 
There are many reasons for eye loss resulting in the need for ocular prosthesis, e.g. trauma, tumors, infections, natal or congenital malformations, end-stage diseases, and postsurgical complications (2). The scientific literature lacks epidemiologic distribution data based on eye loss leading to the use of artificial eyes among certain age groups and between the sexes.

In this study, the distribution of causes of eye loss was analyzed in different age groups and between the sexes. Knowing the causes of eye loss among different age groups would be very important to take precautions to help prevent eye loss.

\section{Methods}

Patients who experienced the loss of one or both eyes due to different causes between 1993 and 2018 were included in this study. All examinations were performed by a single doctor (ŞK) at his private clinic. The medical records of patients were evaluated retrospectively. Patients with incomplete medical records and a lack of reliable clinical data were excluded from this study.

Patients were divided into four age groups as follows: preschool-age (0-6 years, group I), school-age ( $7-12$ years, group 2), adolescence ( $13-20$ years, group 3$)$, and adult age $(\geq 21$ years, group 4). Causes of eye loss were grouped as follows: trauma, postoperative, and other causes, including infection, tumor, and congenital or natal diseases. Patients were evaluated in terms of age, sex, affected eye, and cause of eye loss.

Prior approval from the Ethics Committee was obtained, and written informed consent was given by all patients involved in this study. This study was conducted in accordance with the tenets of the Declaration of Helsinki.

Statistical analysis was performed using the SPSS Ver. 22.0 program (SPSS Chicago, Illinois, USA). Pearson's Chi-square test was used for the comparison of data between groups. Data were considered significant at $\mathrm{p}<0.05$.

\section{Results}

A total of 816 patients (504 men, 312 women) with eye loss were included in this study. The mean age was $12.6 \pm 13.6$ (range, 0-76) years. The distribution of patients according to ages was as follows: 317 patients (38.8\%) in group I, 214 patients (26.2\%) in group 2, 107 patients (13.1\%) in group 3, and 178 patients $(21.8 \%)$ in group 4.

The overall number of patients with eye loss tended to decrease by age. After age 20 years, it tended to increase again but not as high in numbers as in those aged under six years (Table I).

Trauma was the most frequent cause of eye loss (71.9\%) among all the patients $(p<0.00 \mathrm{I})$, followed by other causes (I5.9\%), such as a tumor, infection, and natal diseases, and the least seen eye loss etiology was postoperative problems (Table 2).

The most frequent etiologic factor of eye loss individually in each group was also trauma. The second most frequent cause of eye loss in group I was other causes, whereas among patients aged over 12 years (groups 3 and 4), the second most frequent cause was postoperative problems $(p<0.00 \mathrm{I})$.

According to the etiology, trauma, postoperative problems, and other causes, such as infection, tumor, or natal diseases, were seen significantly more frequently in group I ( $31.2 \%, 40.4 \%$, and $72.3 \%$, respectively) $(p<0.001$ ).

The percentage of trauma tended to increase by age until the age of 20 years. However, after age 20 years, the predominance of traumatic etiology tended to decrease, whereas other causes of eye loss increased. However, trauma was still the most important etiologic factor in this age group (Table 3).

Regarding the distribution by sex, traumatic etiologies were more frequently seen in males $(68 \%)$, whereas other causes (infection, tumor and natal diseases) of eye loss were

Table I. Demographic features of the patients according to age groups

\begin{tabular}{lccccc} 
& Group I (Preschool) & Group 2 (School) & Group 3 (Adolescence) & Group 4 (Adulthood) & Total \\
\hline Number of patients, $\mathrm{n}(\%)$ & $317(38.8)$ & $214(26.2)$ & $107(13.1)$ & $178(21.8)$ & $816(100.0)$ \\
Sex, $\mathrm{n}(\%)$ & & & & \\
$\quad$ Male & $160(50.5)$ & $127(59.3)$ & $86(80.4)$ & $131(73.6)$ & $504(61.8)$ \\
Female & $157(49.5)$ & $87(40.7)$ & $21(19.6)$ & $47(26.4)$ & $312(38.2)$ \\
P & 0.910 & 0.005 & $<0.001$ & $<0.001$ & $<0.001$ \\
Side, $\mathrm{n}(\%)$ & & & & \\
Right & $169(53.3)$ & $106(49.5)$ & $56(52.3)$ & $86(48.3)$ & $417(51.1)$ \\
Left & $148(46.7)$ & $108(50.5)$ & $51(47.7)$ & $92(51.7)$ & $399(48.9)$ \\
P & 0.238 & 0.891 & 0.629 & 0.653 & 0.529 \\
\hline
\end{tabular}


Table 2. Demographic characteristics of the patients according to etiologies

\begin{tabular}{|c|c|c|c|c|}
\hline & Trauma & Postoperative & $\begin{array}{l}\text { Other (infection, } \\
\text { tumor, congenital) }\end{array}$ & Total \\
\hline Number of patients, n (\%) & 587 (7I.9) & $99(12.1)$ & $130(15.9)$ & $816(100.0)$ \\
\hline Age, yrs; mean $\pm S D$ (range) ${ }^{\dagger}$ & $12.9 \pm 11.6(0-62)$ & $16.6 \pm 19.8(0-73)$ & $8.2 \pm 15.3(0-76)$ & $12.6 \pm 13.6(0-76)$ \\
\hline \multicolumn{5}{|l|}{ Sex, n (\%) } \\
\hline Male & $399(68)$ & $50(50.5)$ & $55(42.3)$ & $504(61.8)$ \\
\hline Female & $188(32)$ & $49(49.5)$ & $75(57.7)$ & $312(38.2)$ \\
\hline $\mathrm{P}$ & $<0.001$ & 0.920 & 0.079 & $<0.001$ \\
\hline \multicolumn{5}{|l|}{ Side $(p=0.331), n(\%)$} \\
\hline Right & $303(51.6)$ & $44(44.4)$ & $70(53.8)$ & $4 \mid 7(5 I .1)$ \\
\hline Left & $284(48.4)$ & $55(55.6)$ & $60(46.2)$ & $399(48.9)$ \\
\hline $\mathrm{P}$ & 0.433 & 0.269 & 0.380 & 0.529 \\
\hline
\end{tabular}

†SD: Standard Deviation.

Table 3. Comparison of etiological factors with age groups

\begin{tabular}{|c|c|c|c|c|}
\hline & Trauma & Postoperative & $\begin{array}{l}\text { Other (infection, } \\
\text { tumor, congenital) }\end{array}$ & Total \\
\hline Group I (Preschool), n (\%) & $183(57.7)$ & $40(12.6)$ & $94(29.7)$ & $317(100)$ \\
\hline Group 2 (School), n (\%) & $174(81.3)$ & $20(9.3)$ & $20(9.3)$ & $214(100)$ \\
\hline Group 3 (Adolescence), n (\%) & $96(89.7)$ & $9(8.4)$ & $2(1.9)$ & $107(100)$ \\
\hline
\end{tabular}

$\mathrm{n}$ : Number of the patients.

seen more in the female population $(57.7 \%)(p<0.00 \mathrm{I})$ (Table 2). On the other hand, in all age groups except group I, eye loss was seen significantly more frequently in males than in females, and the highest male predominance for eye loss was in group 3. The female predominance was the highest in group I $(p<0.00 \mathrm{I})$ (Table I).

There was no significant difference concerning the affected side of patients according to age groups, sex, or etiology of eye loss $(p=0.694, p=0.096, p=0.33 \mathrm{I})$.

\section{Discussion}

In this study, the most recent data of prosthesis wearers in the scientific literature according to age, sex, and cause of ocular prosthesis use were analyzed. The findings of this study showed that the most frequent eye loss etiology was trauma to the globe. These results are consistent with other studies. Modugno et al. (2) examined 8018 ocular prosthesis wearers, with the largest number of patients examined and found that the overall incidence of traumatic eye loss was $54 \%$. Coas et al. (3) examined 238 patients and verified the $57.1 \%$ of the injuries were of traumatic origin. Erie et al. (6) enrolled $\mathrm{IOI}$ enucleated eyes in their study and reported that trauma $(35 \%)$ was the most frequent etiology for enucleation. Haile et al. (7) studied the causes of eye removal in 282 patients in Ethiopia and found that the most common cause was traumatic globe rupture (33\%). Another study was conducted in Uganda by Davanger, with 207 patients who had undergone previous enucleation surgeries, and the author found similar results to other studies, reporting the traumatic eye removal percentage as $50.7 \%$ (8). The most recent study was performed by Moreno-Caviedes et al. (9) The authors claimed that $51 \%$ of the eyeball loss in Colombia was because of trauma. By contrast, some studies reported that only a small percentage of patients' eye loss arose from trauma (I0). Gunalp et al. (I I) reported a very large series of enucleation surgeries (3506 enucleations of 3482 patients), declaring that the most frequent enucleation etiology was tumors (33.8\%), whereas the percentage of traumatic etiology for enucleation was $6 \%$.

In the present study, the traumatic eye loss percentage tended to increase until the age of 20 years but then decreased despite still being the most significant eye loss etiol- 
ogy. This can be explained by preventative measures against accidents and increased consciousness with age. Therefore, the prevention of work-related or any other kinds of injuries is very important for public health.

When the groups were examined according to age distribution, the highest number of eye loss cases was seen in group I, independent of etiology. The number of patients experiencing eye loss decreased with increasing age till age 20 years. Thereafter, a slight increase in number was seen but not as high as in group I. There are many different age-related eye loss studies with different results. Gunalp et al. claimed that enucleation occurred mostly among patients aged younger than nine years (II). Cole et al. (I2) studied perforating eye injuries caused by darts and found that most were seen before age I4 years. Quandt et al. (13) showed that most patients with occupational eye injuries among farmers were aged 30 to 39 years. Another study that was conducted by Vienstenz et al. (14) examined work-related trauma and declared that the mostly seen injury age group was 10-29 years. Mcgwin et al. (I5) claimed that patients aged between 20 and 40 years were more exposed to eye injuries compared with other ages. Cillino et al. (16) showed that patients aged under 50 years were more susceptible to eye injuries, whereas Moreno et al. (9) reported that eye loss was seen more frequently in Colombia in patients aged over 40 years.

Regarding the distribution by sex, males were at greater risk for eye loss. This result is consistent with many other studies $(6-9,1 \mid-14,16)$. Traumatic etiologies were more frequent in the male population, whereas the incidence of other causes, such as infection, tumor, and congenital or natal diseases, was higher in the female population. Postoperative etiologies did not differ in frequency according to sex. Modugno et al. (2) showed that work-related eye injuries were observed more frequently in male workers. However, other causes of eye loss in their study showed no statistically significant difference between the sexes. Coas et al. (3) claimed that congenital and traumatic etiologies were seen more frequently in males, but pathogenic etiology was higher among female patients. Another noteworthy finding in the current study was that male sex predominance became higher after age of six years; before that age, both sexes experienced eye loss equally.

In conclusion, this study shows that male sex is prone to accidents resulting in eye loss, with young adult males, in particular, being exposed to work-related injuries. Thus, preventative measures are very important to reduce the risks of eye loss and to reduce the loss of the occupational workforce.

\section{Disclosures}

Acknowledgements: I would like to thank Prof. Dr. Şafak Karslıoglu for providing the medical records of the patients examined in his own private clinic.
Ethics Committee Approval: The Ethics Committee of Istanbul Haseki Training and Research Hospital provided the ethics committee approval for this study (13.1I.2019-2019/4I).

Peer-review: Externally peer-reviewed.

Conflict of Interest: None declared.

\section{References}

I. Artopoulou II, Montgomery PC, Wesley PJ, Lemon JC. Digital imaging in the fabrication of ocular prostheses. J Prosthet Dent 2006;95:327-30. [CrossRef]

2. Modugno A, Mantelli F, Sposato S, Moretti C, Lambiase A, Bonini S. Ocular prostheses in the last century: A retrospective analysis of 8018 patients. Eye (Lond) 2013;27:865-70. [CrossRef]

3. Côas VR, Neves AC, Rode Sde M. Evaluation of the etiology of ocular globe atrophy or loss. Braz Dent ] 2005;16:243-6. [CrossRef]

4. Dyer NA. the Artificial Eye. Aust J Ophthalmol 1980;8:325-7.

5. Gibson $\mathrm{T}$. The prostheses of Ambroise Paré. Br J Plast Surg 1955;8:3-8. [CrossRef]

6. Erie JC, Nevitt MP, Hodge D, Ballard DJ. Incidence of enucleation in a defined population. Am J Ophthalmol 1992;1 13:13844. [CrossRef]

7. Haile M, Alemayehu W. Causes of removal of the eye in Ethiopia. East Afr Med J 1995;72:735-8.

8. Davanger M. Causes of enucleation in Uganda. $\mathrm{Br} J$ Ophthalmol 1970;54:252-5. [CrossRef]

9. Moreno-Caviedes FH, Velez Cuellar N, Caicedo Zapata M, Triana Reina G, Sánchez A. Characterization of Eyeball Loss in Four Cities of Colombia. Cureus 2017;9:e1677. [CrossRef]

10. Setlur VJ, Parikh JG, Rao NA. Changing causes of enucleation over the past 60 years. Graefes Arch Clin Exp Ophthalmol 2010;248:593-7. [CrossRef]

I I. Günalp I, Gündüz K, Ozkan M. Causes of enucleation: A clinicopathological study. Eur J Ophthalmol 1997;7:223-8. [CrossRef]

12. Cole MD, Smerdon D. Perforating eye injuries caused by darts. Br J Ophthalmol. 1988;72:5 I I-4. [CrossRef]

13. Quandt SA, Schulz MR, Talton JW, Verma A, Arcury TA. Occupational Eye Injuries Experienced by Migrant Farmworkers. J Agromedicine 2012;17:63-9. [CrossRef]

14. Viestenz A, Küchle M. [Retrospective analysis of 417 cases of contusion and rupture of the globe with frequent avoidable causes of trauma: the Erlangen Ocular Contusion-Registry (EOCR) 1985 - 1995]. [Article in German]. Klin Monbl Augenheilkd 200।;218:662-9. [CrossRef]

15. McGwin G Jr, Owsley C. Incidence of emergency department-treated eye injury in the United States. Arch Ophthalmol 2005; 123:662-6. [CrossRef]

16. Cillino S, Casuccio A, Di Pace F, Pillitteri F, Cillino G. A five-year retrospective study of the epidemiological characteristics and visual outcomes of patients hospitalized for ocular trauma in a Mediterranean area. BMC Ophthalmol 2008;8:6. [CrossRef] 